7. Child Lang. 4I (2014), 780-81 o. (C) Cambridge University Press 2013. The online version of this article is published within an Open Access environment subject to the conditions of the Creative Commons Attribution-NonCommercial-ShareAlike licence $<$ http://creativecommons. org/licenses/by-nc-sa/3.०/>. The written permission of Cambridge University Press must be obtained for commercial re-use.

doi:10.1017/So305000913000196

\title{
Effects of focus and definiteness on children's word order: evidence from German five-year-olds' reproductions of double object constructions*
}

\author{
BARBARA HÖHLE, ROBIN HÖRNIG, THOMAS WESKOTT, \\ SELENE KNAUF AND AGNES KRÜGER \\ University of Potsdam
}

(Received 4 March 201 I - Revised I I Fanuary 2012-Accepted I March 2013-

First published online 27 Fune 2013)

\section{ABSTRACT}

Two experiments tested how faithfully German children aged 4;5 to $5 ; 6$ reproduce ditransitive sentences that are unmarked or marked with respect to word order and focus (Expr) or definiteness (Exp2). Adopting an optimality theory (OT) approach, it is assumed that in the German adult grammar word order is ranked lower than focus and definiteness. Faithfulness of children's reproductions decreased as markedness of inputs increased; unmarked structures were reproduced most faithfully and unfaithful outputs had most often an unmarked form. Consistent with the OT proposal, children were more tolerant against inputs marked for word order than for focus; in conflict with the proposal, children were less tolerant against inputs marked for word order than for definiteness. Our results suggest that the linearization of objects in German double object constructions is affected by focus and definiteness, but that prosodic principles may have an impact on the position of a focused constituent.

\section{INTRODUCTION}

A child learning a language is not only confronted with the task of acquiring the phonological, morphosyntactic, lexical, and semantic aspects of the

[*] This research was funded by the DFG (German Science Foundation) by a grant to Barbara Höhle as part of the SFB 632 Information Structure: The linguistic means for structuring utterances, sentences and texts. We thank all colleagues from the SFB - especially Frauke Berger and Antje Sauermann - for their support. Special thanks go to the children and their parents for their participation in the study. Address for correspondence: Barbara Höhle, University of Potsdam-Linguistics Department, Karl-Liebknechstr. 24-25 Potsdam I4755, Germany. e-mail: hoehle@uni-potsdam.de 
grammatical system of the language, but also how this system should be instantiated in various discourse contexts. Generally speaking, the task the child has to master in this area is to find out how a given meaning should be encoded in an optimal way within a given communication setting. The choice of an optimal way to transfer a meaning by a verbal utterance requires the integration of several components of the linguistic system, among them the pragmatics, syntax, and phonology of the utterance. This integration requirement can be considered as an interface phenomenon par excellence, posing a special challenge to the child. In addition, the linguistic coding of information structure is subject to a high degree of optionality, resulting in considerable ambiguity and variation in the child's input. This in turn may make it hard for the child to discover the relevant form-function mappings. This is in accordance with the fact that the acquisition of competences related to aspects of information structure and pragmatics has been described to be a longer lasting process (e.g., Hickmann, Hendricks, Roland \& Jiang, I 996; Musolino \& Lidz, 2006; Schaeffer \& Mathewson, 2005; Trueswell, Sekerina, Hill \& Logrip, I999). In this paper, we take a closer look at German children's acquisition of word order as one of the linguistic devices to mark information structure. We report the results of two experiments using an imitation task that tested whether focus and definiteness have differential impacts on five-year-olds' ordering of the objects in double object constructions.

Across different languages it has been observed that there is a strong tendency to place given information, i.e., information that is assumed by the speaker to be shared with the hearer as a result of the preceding discourse, before new information (Clark \& Haviland, I977). There is evidence that this ordering preference is related to properties of the human information processing system: sentence comprehension seems to be affected by ordering information in this way (faster integration of new information together with reduced memory load). Similarly, prior mentioning of a referent facilitates its production in subsequent utterances (e.g., Bock \& Irwin, I 980; Ferreira \& Yoshita, 2003) in adults. Yet word order is certainly not the only linguistic device that is related to information structure. In many languages, new or focused information is prosodically more prominent than given or non-focused information (Gussenhoven, I983; Selkirk, I995). The discourse status of a referent as given or new can also be marked by the choice of the referring expression. While given referents are usually referred to by definite DPs or pronouns, new referents are often introduced into the discourse by means of indefinite DPs (e.g., Chafe, I976; Clark \& Haviland, I977; Heim, I982). In many languages, however, the function of definiteness is not restricted to marking discourse status, but it is rather linked to a mixed bag of properties going under the label 'specificity', among them, depending on theoretical predilection, discourse givenness, 
familiarity, identifiability, existence, and uniqueness (see Lyons, I999). Notwithstanding this plurality of functions that definiteness may perform, one of the tasks of a child learning a language that marks definiteness in its determiner system is to acknowledge the fairly stable correlation between discourse status and definiteness: indefinites (usually) mark newness, while definites (usually) mark givenness. In a similar vein, the (in)definiteness and other form-related aspects of newness - focus, prosodic prominence, and a proclivity for the right periphery of clauses - go hand in hand.

To date, research on children's acquisition of information structure does not provide a coherent picture of the developmental timecourse for any of these aspects in children's language production. Intonational markings to highlight new or focused information have been shown to be used by children from age two to four years onwards (Hornby \& Hass, I970; MacWhinney \& Bates, ı978; Müller, Höhle, Schmitz \& Weissenborn, 2006; Sauermann, Höhle, Chen \& Järvikivi, 20ı i Wieman, ı 976; Wonnacott \& Watson, 2008). But the accent types and the phonetic means that children of school age use to render a new or focused constituent prosodically more salient still show some deviation from adults' performance (Chen, 20I I; de Ruiter, 2010). Furthermore, the marking of more subtle differences between different kinds of focus (e.g., contrastive vs. new) may take some more time to develop (Sauermann et al., $20 \mathrm{I}$ I).

With respect to children's marking of givenness in referring expressions, the picture is not much clearer. Some studies provide evidence for an adequate marking of definiteness in referring expressions in discourse or narrative utterances from age three onwards (e.g., Emslie \& Stevenson, I 98 I ; Maratsos, I974; Power \& Dal Martello, I986), others find non-adultlike choices, like the introduction of new referents with definite DPs, up to the age of nine years (Hickmann et al., r 996; Kail \& Hickmann, I992; Kail \& Sánchez y López, I997). The reason behind the inconsistency of these findings may be sought in methodological differences, as well as language-particular factors, since the evidence comes from studies using different kinds of empirical methods for studying children with various language backgrounds.

A similarly heterogeneous picture arises from studies on children's use of word order, which produced evidence for both linearization preferences: placing given before new information, as well as new information before given. In a cross-linguistic study, Hickmann et al. (I996) analyzed elicited narratives from Chinese, English, French, and German seven- to ten-year-old children and adults with respect to their placement of new vs. given subjects in relation to the position of the verb. Overall, their data showed a preference for placing new subjects postverbally, but there was a lot of variation across the languages considered, and the involvement of different factors on both the sentence and the discourse level precludes any 
straightforward conclusion as to how children use word order to encode givenness.

Narasimhan and Dimroth (2008) investigated the ordering of given and new information in three- and five-year-old German-speaking children. In their study, productions of coordinated DPs with one new and one given referent were elicited. In contrast to adults, who followed the expected given-new order in most cases, children of both age groups produced significantly more new-given orders than given-new orders.

Stephens (2010) provides a detailed study of the effect of givenness on children's ordering of arguments in English constructions with dative alternations in four-year-olds (She gave the hat to the man vs. She gave the man the hat; see e.g., Bresnan, 2007) and locatives in three- and five-year-olds (She squirted the ketchup on the hotdog vs. She squirted the hotdog with ketchup). She employed a task in which children answered a question about a scene presented on a video clip in which one of the arguments was mentioned (e.g., What's the girl doing with the ketchup/with the hotdog?). All age groups showed a preference for placing given before new information. But the strength of this effect was clearly influenced by the verb type and the construction type. In dative alternations, for example, the children already preferred the prepositional dative when the theme and the recipient were both new $(73 \%$ if the agent was given and $94 \%$ if the location was given; cf. Stephens, 2010: 9I), such that the further increase to $\mathrm{I} 00 \%$ with a given theme and a new recipient (given-theme-beforenew-recipient) was less pronounced than the decrease to $42 \%$ with a given recipient and a new theme (new-theme-before-given-recipient). In contrast, $67 \%$ of the double object constructions from the children showed a given-before-new (recipient-first) ordering suggesting that givenness has a higher impact on the production of double objects than of prepositional dative constructions compared to the control conditions. In addition, word order as a function of givenness was highly correlated with the choice of referring expressions, as the majority of given arguments were realized as pronouns. Definiteness of full DPs did not seem to play an independent role in construction choice, but the set of data relevant for this (constructions with both arguments realized as full DPs) was rather small in the sample. Thus it is still considered to be an open question whether children's choice of word order is influenced by the discourse status of the arguments or indirectly through the choice of referring expressions, with placing short constituents - like pronouns-before longer constituents - like full DPs - which may have a separate effect on ordering (at least in the child grammar).

Taking an approach similar to Stephens (2010), de Marneffe, Grimm, Arnon, Kirby and Bresnan (2012) analyzed spontaneous productions of instances of the dative alternation from seven two-to five-year-old English 
children taken from the CHILDES database. In their corpus sample, pronominalization of both theme and recipient had a significant impact on the dative alternations of children, whereas givenness had no significant main effect. In contrast, the child-directed speech of adults showed an influence of all three predictors, pronominalization of theme and recipient, as well as givenness of theme. However, the influence of givenness of theme is blurred: in a joint analysis of children's and adults' data a significant influence of givenness of theme was again found, which did not interact with group and thus does not support a differential effect of givenness on children and adults.

Our studies set out to have a closer look at two factors that are influenced, though not fully determined, by discourse status, and to investigate their effects on children's word order of double objects in German: focus and definiteness. We used an imitation task to control the differential assessment of focus and definiteness, although the former was not manipulated independently of discourse status. To study the effect of these two factors independently from the choice of the referring expression (i.e., pronominalization) and its impact on word order, the stimulus sentences featured two full DPs as either the direct and indirect object. Experiment I tested the effect of focus on children's word order preferences; the focused constituent, the direct or indirect object, was prosodically marked by a focus accent in congruence with a preceding constituent question. Experiment 2 examined the effect of definiteness on children's ordering of the objects by presenting the target sentences as answers to a broad information focus question (What happened?). Before presenting these studies, we introduce some ordering principles that regulate German ditransitive structures according to proposals known from the linguistic literature.

In comparison to languages like English, German exhibits a relatively free word order. This relative freedom includes (but is not restricted to) the placement of arguments in the so-called MidDLE FIELD ('Mittelfeld'), that is, the syntactic domain between the head of CP (filled by a complementizer in verb-final sentences, and by the finite verb in verb-second sentences of German), and the head of VP (which is identifiable by the finite verb in verb-final sentences). Word order in the German middle field shows a considerable degree of optionality: in sentences with three full DP arguments (subject $\mathrm{S}$, indirect object $\mathrm{IO}$, and direct object DO, as in sentences with ditransitive verbs), all six possible permutations of the arguments are grammatical, even though some of them are distinctly marked (e.g., IO $<$ DO $<\mathrm{S}$ ). According to current theorizing, every order which deviates from the canonical order $\mathrm{S}<\mathrm{IO}<\mathrm{DO}$ has to be derived by a clause-bound movement operation, 'scrambling' (Ross, i 967; but see Fanselow, 200 I, for a base-generation account). The conditions on scrambling have been the matter of much controversy. There have been countless attempts to derive 
the markedness differences from a number of different conditions on linearization, among them that definite DPs tend to precede indefinite ones, that pronominalized arguments precede full argument DPs, that animates precede inanimates, and that non-focused (background) material precedes focused constituents (see Büring, 200I ; Höhle, I982; Lenerz, I977; Reis, I987; Uszkoreit, I986; to name only a few). All these accounts have in common that the markedness of a given argument order in the middle field is dependent on the compliance with the linearization conditions - the more conditions it violates, the more marked is the order.

A framework that has been argued to be particularly suited to deal with this problem is Optimality Theory (OT; cf. Prince \& Smolensky, I 993; for an introduction to O'T syntax, see Legendre, Grimshaw \& Vikner, 200 I). In OT, markedness is the direct reflection of the relative ranking of markedness constraints which are used to evaluate a set of output candidates (i.e., syntactic structures) generated by the grammar from some underlying input representation (i.e., an interpretation; note that we ignore the influence of faithfulness constraints, since it is orthogonal to our line of argument). The optimal (and, accordingly, least marked) candidate from a candidate set of outputs is, loosely speaking, the one that violates the least number of higher ranked constraints. All other candidates are suboptimal. According to classical OT, suboptimal candidates are ungrammatical, since optionality of a syntactic operation is not allowed for. Extensions to classical OT architecture have sought to deal with this issue. With respect to the optionality of German word order variants, there are two proposals of how the relative freedom of word order can be modelled (Müller, r999, and Keller, 2000). In the following, we will concentrate on Müller's proposal.

Müller ( I 999) proposes a constraint representing a general ban against movement of argument noun phrases (STAY!) which is ranked lower than a constraint SCR-CRIT (standing for 'scrambling criteria') containing conditions which, if fulfilled, allow movement. SCR-CRIT itself consists of a subhierarchy of constraints which essentially are renderings of Uszkoreit's ( 1986) linear precedence rules in the guise of OT constraints. The constraint subhierarchy of SCR-CRIT (see ( I) below) demands, among other things, that constituents marked positively for nominative, definiteness, animacy, and dative precede those marked negatively for the respective dimensions; the reverse holds true for constituents marked for focus, where $[-$ foc $]$ should precede $[+$ foc $]$ :

(i) SCR-CRIT: In the VP domain,
a. NOM (Nominative constraint): [+ nom] precedes [-nom]
b. DEF (Definiteness constraint): $[+\mathrm{def}]$ precedes $[-\mathrm{def}]$
c. AN (Animacy constraint): [+ animate] precedes [-animate]
d. FOC (Focus constraint): [ - focus $]$ precedes [+ focus $]$
e. DAT (Dative constraint): $[+$ dat $]$ precedes $[-$ dat $]$ 
The ranking of these constraints proposed by Müller is :

\section{$\mathrm{NOM}>\mathrm{DEF}>\mathrm{AN}>\mathrm{FOC}>\mathrm{DAT}$.}

We want to point out that there are two more constraints in Müller's subhierarchy which, however, are not of interest for our current purposes, and which we decided not to consider. In what follows, we concentrate on the interplay between the constraints DAT, DEF, and FOC from the subhierarchy, since these are the ones that our experiments were concerned with. Note that, in our examples, NOM is always fulfilled because the subject occupies the Vorfeld position; and that Müller's animacy constraint AN is confounded with DAT, since the direct objects in our examples (as well as in the experimental materials to be reported below) are always inanimate, while the indirect objects are always animate. Thus, AN was always violated if DAT was.

Müller's proposal accounts in a theoretically elegant way for the problem that some argument linearizations are marked: violations on the subhierarchy only induce markedness, not ungrammaticality (see Müller, I 999: 795f.). We will exemplify how this works below.

Apart from its theoretical appeal with respect to the domain of word order in the German middle field, we chose the OT approach as our theoretical vantage point because we take this framework to be particularly suitable for thinking about the experimental paradigm we used to investigate the acquisition of word order in German, elicited imitation. Glossing over the exact details of this paradigm for the time being, participants in such experiments are presented with an input sentence and are asked to reproduce this sentence. In the following, we will use the term OUTPUT SENTENCE for the participant's reproduction. An important dependent variable in these experiments is what we call the FAITHFulness of the participants' output (not to be confused with the technical OT term): an output is faithful to its input if it shares the same form. This variable is indexed by the proportion of faithful input-output pairs. The faithfulness of the output to the original input sentence is taken to reflect, among other things, the degree to which the input sentence conforms to the child's grammar: if the input is grammatical and unmarked, it is more likely to be reproduced faithfully than if it is marked or even ungrammatical (cf. Barbier, 2000; Lust, Flynn \& Foley, I 996). Of course, we are fully aware that the OT account neither can, nor intends to, model the actual language production process which takes place during the elicited imitation task. Neither do we want, at this point, to enter into speculations about the acquisition of the linearization preferences, or the constraints possibly underlying them. Still, we think that the OT constraints, or some equivalent abstract representation of the structural restrictions on argument ordering, have to be a part of the overall process that we have to assume in order to explain the task performance of 
our participants. One may conceive of this process in the following way: some mental representation (i.e., the interpretation) of the input sentence, which is the result of the perception process, is checked against the grammar and is passed on to reproduction. Faithful reproduction is easier if the given representation conforms to the principles of grammar than if it does not. Given the OT architecture, one can conceive of this checking process as a kind of filtering: the representation of the input sentence is being passed through the hierarchy of constraints; and the more severe constraint violations it incurs, the harder it is to reproduce faithfully, i.e., the less likely it is that the output form will be identical to the input form. To illustrate how this works, consider the German ditransitive sentence (2b) with a marked order of the two objects in the middle field:
a. Der Mann hat einem Jungen den Ball gegeben. The $_{\text {nom man has }} \mathrm{a}_{\mathrm{dat}}$ boy the $\mathrm{acc}_{\mathrm{b}}$ ball given.
'The man has given a boy the ball.'
b. Der Mann hat den Ball einem Jungen gegeben. The $_{\text {nom man has the }}$ acc ball $\mathrm{a}_{\mathrm{dat}}$ boy given. 'The man has given the ball to a boy.'
c. Der Mann hat dem Jungen einen Ball gegeben. The $_{\text {nom }}$ man has the dat $_{\text {boy }} \mathrm{a}_{\text {dat }}$ ball given.
'The man has given the boy a ball.'

While (2c) represents an unmarked sentence which conforms to both the DAT and the DEF constraint, the direct object den Ball has been moved (scrambled) from its base position to a position to the left of the indirect object in (2b). The DAT constraint on the SCR-CRIT subhierarchy accounts for the marked word order of (2b). Please note that, for expository purposes, we ignore the fact that (2b), apart from violating the DAT constraint, also violates the AN constraint stating that animates should precede inanimates. Strictly speaking, the markedness of (2b) opposite (2c) may result from the violation of either of the two constraints. We will return to this point below. Now, if this sentence is reproduced by a child in an elicited imitation experiment, it is, compared to its unmarked word order counterpart (2a), more likely to be reproduced unfaithfully by, for example, changing the marked order acc $<$ dat to the unmarked order dat $<$ acc in the imitation. But if we take into account the DEF constraint of SCR-CRIT in addition to DAT, the prediction about the faithfulness of reproduction of the two sentences is reversed: (2a) violates DEF (because the indefinite argument precedes the definite one), while complying to DAT (because the IO precedes the DO). In (2b), DEF is fulfilled, while DAT is violated. Given the constraint ranking proposed by Müller ( I999), where DAT is ranked lower than DEF, (2b) wins the competition against (2a). Hence, (2b) is less marked than (2a) and we would predict a higher proportion of faithful 
reproductions for $(2 \mathrm{~b})$ than for $(2 \mathrm{a})$. This can be illustrated by a slimmeddown version of an O'T tableau like the following:

$\mathrm{NOM}>\mathrm{DEF}>\mathrm{FOC}>\mathrm{DAT}$

(2) a. Der Mann hat einem Jungen den

Ball gegeben.

b. Der Mann hat den Ball einem

Jungen gegeben.

If a sentence violates one of the constraints in the first row, the respective column is marked with an asterisk. Sentence (2a) is suboptimal relative to (2b) because it violates the constraint DEF, which is ranked higher than the constraint DAT violated by the competitor (2b).

This point can be further illustrated by considering two output forms with marked word order, which differ with respect to another constraint of SCR-CRIT: FOC. In (3) below, small capitals are to be read as representing narrow foci marked by a falling nuclear accent.

(3) a. Der Mann hat den Ball dem Jungen gegeben. The $_{\text {nom man has the }}$ ball the dat $_{\text {boy }}$ given.

'The man has given the ball to the boy.'

b. Der Mann hat den BALL dem Jungen gegeben. The $_{\text {nom man has the }}$ ball the $\mathrm{dat}_{\mathrm{acc}}$ boy given.

'It was the ball that the man has given to the boy.'

As noted above, both (3a) and (b) exhibit marked word order in the middle field, since they violate the DAT constraint of the SCR-CRIT subhierarchy. They differ only in their performance with respect to the FOC constraint: while ( 3 a) obeys the constraint that foci have to be realized on the phrase occupying the rightmost and most deeply embedded phrase left-adjacent to the lexical verb, (3b) violates this constraint. According to Müller's theory, then, we would have to consider both structures in (3) as marked; but, in addition, $(3 \mathrm{~b})$ is hypothesized to be more strongly marked, since it incurs two violations (FOC and DAT) on the subhierarchy, while (3a) incurs only one (DAT).

(3) a. Der Mann hat den Ball dem Jungen gegeben.

$\mathrm{NOM}>\mathrm{DEF}>\mathrm{FOC}>\mathrm{DAT}$

b. Der Mann hat den BALL dem Jungen gegeben.

This violation profile makes a prediction regarding the faithfulness of the output structures in an elicited imitation experiment: (3b) would be more likely to be reproduced unfaithfully than ( $3 a)$, since the former is predicted to be more marked than the latter. At this point, we leave open the question 
whether one has to assume cumulativity of the constraint violations and, accordingly, additivity of the effects on the frequency of faithful reproductions; but we will return to this point in the discussion of the results.

A further qualification has to be added concerning the role of animacy in the ordering of objects in ditransitive constructions. As noted above, we have so far ignored the fact that, for the cases we have looked at, and which are representative of our experimental materials, the two constraints $\mathrm{AN}$ and DAT work in the same direction. In our examples (2) and (3) above using the prototypical transfer verb geben ('to give'), the indirect object argument (the recipient) is animate, and the direct object argument (the theme) is inanimate. In this prototypical case, it is impossible to tell whether the markedness of the marked (b) variants results from a violation of the DAT, or a violation of the AN constraint. Note that, in order to do so, one would have to consider verbs like 'to donate', which allow for inanimate recipients and animate themes as, e.g., in Der Mann spendete dem Waisenhaus den Hamster ('The man donated the hamster to the orphanage'). Apart from these verbs being relatively rare, the events they denote are quite hard to depict, which makes them unsuitable for the kind of experiment that we report on below. Since this conflation of argument roles and their prototypical animacy status holds for all sentences in our materials, we will treat the AN and the DAT constraint as one and will henceforth call this hybrid constraint 'DAT'. We do not want to conceal the influence of animacy by this nomenclature; rather, we want to highlight the difference between factors which we have manipulated, like word order, and factors which we have kept constant, or have otherwise controlled for, like animacy.

To summarize: we chose Müller's OT account as an implementation of the current theorizing about the linearization preferences in the German middle field, because it allows us to think about the relative effects of word order, focus, and definiteness in a transparent way. It further allows us to map the OT-theoretic notion of markedness of word orders in the middle field, cast in terms of constraint violation on the SCR-CRIT subhierarchy, to the main dependent variable in our elicited imitation experiments, namely the faithfulness of an output produced by a participant relative to the input. The relation between the two is straightforward: if a structure is unmarked, it is most likely to be imitated faithfully. With an increase in constraint violations that a given input structure incurs according to Müller's theory, and, accordingly, an increase in markedness, we predict a decrease in the proportion of faithful reproductions. In addition, OT predicts a general dispreference for marked forms. From this we can deduce that, whenever a marked input structure is reproduced unfaithfully, the resulting output structure should be less marked than the input structure. This is to say that, apart from the quantitative prediction about the faithfulness variable, the OT account allows us to generate predictions about the form of an 
unfaithful output depending on the markedness of the input form, which is dependent on the number of the violated constraints, and the relative rank of the constraints violated.

So far, German children's word order preferences have not been considered within this theoretical framework. The question arises whether children's production of word order provides evidence for children's reliance on these constraints. In a first study using an elicited imitation task, we tested whether German-learning five-year-olds' linearization of the two objects in double object constructions complies with the constraint of placing focused information after background information or whether children would adhere to the canonical word order and place the indirect object before the direct object independently of information structure.

\section{EXPERIMENT i : WORD ORDER AND FOCUS}

Experiment I addressed two constraints of Müller's subhierarchy, DAT and FOC, by crossing word order and focus. The word order in the middle field of the input sentences either agreed $\left(\mathrm{IO}_{\mathrm{dat}}<\mathrm{DO}_{\mathrm{acc}}\right)$ or disagreed $\left(\mathrm{DO}_{\mathrm{acc}}<\mathrm{IO}_{\text {dat }}\right)$ with DAT, and the focused constituent either agreed (final argument) or disagreed (prefinal argument) with FOC.

\section{METHODS}

\section{Participants}

Sixteen monolingual typically developing German-speaking children, aged $4 ; 5$ to $5 ; 6$ (mean: 5;2), seven girls and nine boys, participated in the experiment. Children were recruited in a day care centre in Potsdam. Parents filled out a questionnaire enquiring about the language(s) spoken at home, as well as any previous problems in the language development of their child, and gave informed consent. Children who were reported by the parents to show delayed morphosyntactic development were not included in the study. All other children were tested with subtests of two standardized German tests for the diagnosis of developmental disorders (Sprachscreening für das Vorschulalter: Grimm, 2003; Patholinguistische Diagnostik bei Sprachentwicklungsstörungen: Kauschke \& Siegmüller, 2002). Only children performing within their age range in these tests were included in the experimental study.

\section{Materials}

Four lexical sentence variants were constructed for each of the five German ditransitive verbs geben 'to give', bringen 'to bring', schenken 'to donate', 
zeigen 'to show', and wegnehmen 'to take away', resulting in a set of twenty sentences (cf. the 'Appendix'). All sentences were V2 main clauses, beginning with the subject noun phrase $\mathrm{S}$, followed by the finite auxiliary hat 'has', followed by the indirect object IO and the direct object DO in either order in the middle field with the lexical verb as past participle at the end of the sentence (see examples below in (4)). All three noun phrases, S, IO, and DO, were definite. To ensure an unambiguous case marking of the two objects, all direct objects (accusative case, acc) had masculine gender and all indirect objects (dative case, dat) had masculine or neuter gender. Due to the prototypical thematic role properties of the verbs used (see above), the direct objects were inanimate, whereas the indirect objects were animate; subjects were animate, too.

The sentences instantiated four different input forms resulting from crossing word order and focus. Word order is unmarked if dat precedes acc (IO precedes DO), but it is marked if acc precedes dat (DO precedes IO). Focus is unmarked if the focus accent is carried by the last DP, but it is marked if it is carried by the prefinal DP. The input forms are exemplified in (4) with focused constituents printed in small capitals.

(4) a. M-: unmarked input

Der Mann hat $\left[\text { dem }_{\text {dat }} \text { Fungen }\right]_{\mathrm{IO}} \quad\left[D E N_{\mathrm{acc}} \mathrm{BALL}\right]_{\mathrm{focDO}}$ gegeben.

'The man has $\left[\text { the }_{\text {dat }} \text { boy }\right]_{\mathrm{IO}} \quad\left[\mathrm{THE}_{\mathrm{acc}} \mathrm{BALL}\right]_{\mathrm{focDO}}$ given.'

b. $\mathrm{M}+\mathrm{FOC}$ : input marked with respect to focus

Der Mann hat $\left[D E M_{\text {dat }} \text { JunGEN }\right]_{\text {focIO }} \quad\left[\text { den }_{\text {acc }} \text { Ball }\right]_{\mathrm{DO}}$ gegeben.

'The man has $\left[\mathrm{THE}_{\text {dat }} \mathrm{BOY}\right]_{\text {focIO }} \quad\left[\text { the } \text { acc }_{\text {ball }}\right]_{\mathrm{DO}}$ given.'

c. M+DAT: input marked with respect to word order

Der Mann hat $\left[\text { den }_{\mathrm{acc}} \text { Ball }\right]_{\mathrm{DO}} \quad\left[{ }_{\text {DEM }} \text { dat JUNGEN }\right]_{\text {focIO }}$ gegeben.

'The man has $\left[\text { the }_{\text {acc }} \text { ball }\right]_{\mathrm{DO}} \quad\left[\mathrm{THE}_{\mathrm{dat}} \mathrm{BOY}\right]_{\text {focIO }}$ given.'

d. $\mathrm{M}++$ : doubly marked input

Der Mann hat $\left[D E N_{\mathrm{acc}} \mathrm{BALL}\right]_{\mathrm{focDO}} \quad\left[\right.$ dem $_{\mathrm{dat}}$ Fungen $_{\mathrm{IO}}$ gegeben.

'The man has $\left[\mathrm{THE}_{\mathrm{acc}} \mathrm{BALL}\right]_{\mathrm{focDO}} \quad\left[\mathrm{the}_{\mathrm{dat}} \mathrm{boy}\right]_{\mathrm{IO}}$ given.'

Input (4a), $\mathrm{M}-$, is considered unmarked as it combines the unmarked order dat $<$ acc (word order IO $<$ DO) with an unmarked final focus; the prefinal focus renders input $(4 \mathrm{~b})$ marked with respect to focus: $\mathrm{M}+\mathrm{FOC}$; the order acc $<$ dat (word order DO $<\mathrm{IO}$ ) renders input $(4 \mathrm{c})$ marked with respect to word order: $\mathrm{M}+\mathrm{DAT}$; input $(4 \mathrm{~d})$ is doubly marked, that is, with respect to both focus and word order: $\mathrm{M}++$.

Inputs were preceded by a wh-question that enquired about the subsequently focused constituent. The wh-question asked for the direct object $\mathrm{DO}_{\text {acc }}$ when preceding input form (4a) or (4d), and for the indirect object $\mathrm{IO}_{\text {dat }}$ when preceding input form $(4 \mathrm{~b})$ or $(4 \mathrm{c})$, as exemplified for the sample item in (5). 
(5) wh-question asking for the direct object DO preceding (4a) and (4d): -Was hat der Mann dem Fungen gegeben?' What ${ }_{\mathrm{acc}}$ has the man given the ${ }_{\text {dat }}$ boy?'

wh-question asking for the indirect object IO preceding (4b) and (4c): -Wem hat der Mann den Ball gegeben? 'Whom ${ }_{\mathrm{dat}}$ has the man given the acc ball ?'

The eighty stimulus sentences (plus two practice sentences) for the experiment with the children were tape-recorded at the phonetics laboratory of the University of Potsdam. They were read aloud by a twenty-four-yearold male speaker at a slow pace. The focus accent had a falling contour, i.e., a drop in $F_{0}$ (cf. Féry, I 993). The eighty sentences were equally distributed across four lists such that each list included each lexical sentence variant once, and such that all four types of input form appeared equally often within each list. The sentences were supplied with coloured hand-drawn pictures showing the described event. The pictures were filed in a folder which served as a picture book.

\section{Procedure}

The children were tested individually in their daycare centres in a separate quiet room with an elicited imitation task (Lust et al., i 996). The child was seated on a chair next to the experimenter, who introduced the child to the hand puppet Willi, an almost blind mole with impaired hearing, for whom the child was later asked to repeat the sentences. The child was facing a notebook monitor which showed the robot Wall-E (known from Pixar films), who was about to be trained to tell Willi what happens in his favourite picture book (the folder with the picture stimuli). During the session, the mole Willi, together with the child, leafed through the picture book. After turning a page, the mole closely eyed the picture and, due to his inability to recognize the depicted event, asked the wh-question. Thereupon, the experimenter's assistant started the auditory presentation of the corresponding prerecorded sentence from a second notebook via loudspeakers (=input). This was Wall-E's description of the depicted event. Willi, who did not understand Wall-E's response, asked the child Hä? 'Eh?', prompting the child to repeat the sentence (= output). The imitations were recorded by the notebook in front of the child and written down by the second experimenter.

Two practice items were followed by the twenty experimental items in randomized order for each child (no fillers were used).

\section{Hypotheses}

On our basic assumption, faithfulness of input-output pairs decreases as markedness of inputs increases. Hence, our first hypothesis was that 
input-output pairs are most often faithful if the input is unmarked, input form $\mathrm{M}-$, compared to all the other input forms. Our second hypothesis claimed that the two singly marked input forms $\mathrm{M}+\mathrm{FOC}$ and $\mathrm{M}+\mathrm{DAT}$ differ in faithfulness. With Müller's (I999) assumption that the focus constraint is ranked higher than the word order constraint, we predicted fewer faithful pairs for input M+FOC than for input M+DAT. Note that, if the conflation of animacy and word order discussed above were to drive the results, we would predict the opposite pattern, since the animacy constraint $\mathrm{AN}$ is ranked higher than FOC. Third, we were interested in whether the doubly marked input $\mathrm{M}++$ is least faithful, that is, less faithful than the more strongly marked form of the two singly marked inputs. All these issues are addressed simultaneously by analyzing faithfulness as a function of input forms, which are ordered in descending order of observed faithfulness.

In addition to the faithfulness analysis, we examined unfaithful input-output pairs. According to the rationale behind the elicited imitation task, outputs of unfaithful input-output pairs can be expected to be less marked than their inputs. Unfaithful pairs were categorized according to whether or not they meet this expectation, and it was determined whether expected input-output pairs are significantly more frequent than unexpected input-output pairs (unfaithful pairs with outputs not less marked than their inputs). This was tested statistically via a one-sample $t$-test.

All statistical tests were performed on square-root-arcsine transformed relative frequencies; descriptive statistics are presented as untransformed relative frequencies (in percentages).

\section{RESULTS AND DISCUSSION}

Invalid outputs like deviating or ungrammatical structures were excluded from the analysis. Ten German native speakers independently judged the valid outputs for focus accent position; outputs without reliable focus judgements were excluded from the analysis. Twelve of the twenty excluded utterances were discarded due to hesitations in regions critical to determining the focus accent; three further utterances were sorted out because of problems in identifying the focus accent (two times the raters disagreed on the accent and one time the accent was placed on the verb). Three utterances were rejected because the 'recipient' was realized as a PP instead of an NP, all of them with the verb wegnehmen 'to take away', e.g., Der Räuber hat den Schuh von den Clown weggenommen, verbatim: 'The robber has the shoe from the clown away-taken'. The last two utterances were excluded because of an illicit word order. In one case, an object NP was fronted and then the subject, the indirect object, and the direct object were enumerated after the verb (Den Edelstein geschenkt, die Eule den Raben den Edelstein, 


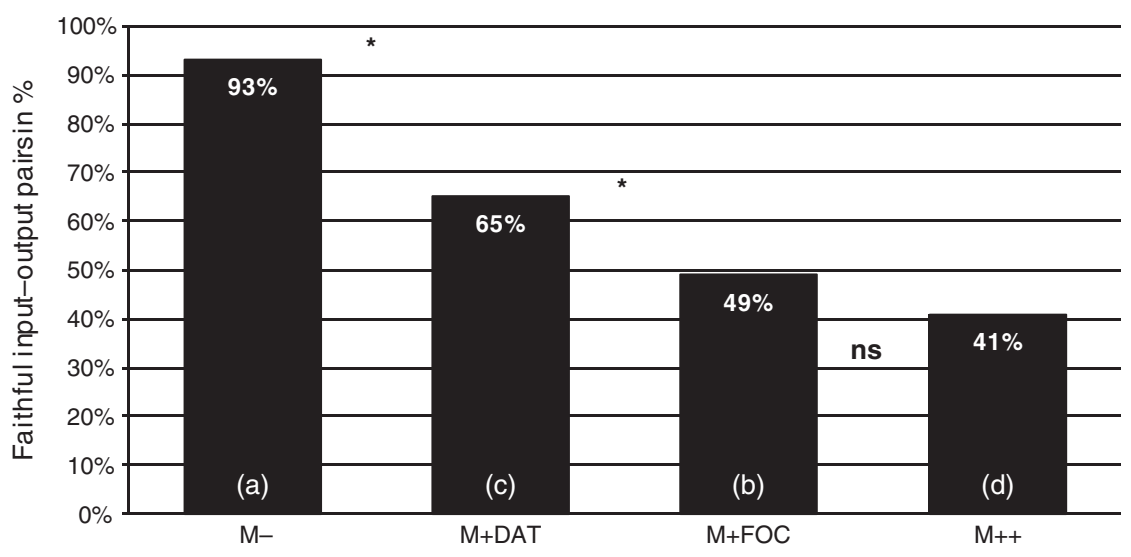

Fig. I. Relative frequencies (in \%) of faithful input-output pairs in Experiment I as a function of input form (markedness for word order or/and focus). An asterisk between neighboured bars indicates a significant difference (ns=non-significant).

verbatim: 'The gemstone donated, the owl the raven the gemstone'). In the last case, an object NP was extraposed into the 'Nachfeld', i.e. the region to the right of the lexical verb (Dis Schaf hat die Socke weggenommen dem Mädchen, verbatim: 'The sheep has the sock taken-away the girl'). The twenty discarded utterances were distributed among the conditions as follows: $\mathrm{M}-:$, $, \mathrm{M}+\mathrm{DAT}: 6, \mathrm{M}+\mathrm{FOC}: 2, \mathrm{M}++: 7$.

Three hundred out of 320 input-output pairs (94\%) remained for the faithfulness analysis; I 86 of them $(62 \%)$ were faithful. The statistical analysis confirmed that faithfulness differed for the four input forms $\left(F(3,45)=\mathrm{I} 3 \cdot 78, p<\cdot 00 \mathrm{I}, \eta^{2}=\cdot 48\right)$. For the computation of orthogonal paired comparisons, the input forms were ordered in descending degree of faithfulness on a single four-level factor with the unmarked input being most faithful and thus leftmost and faithfulness descending from left to right (see Figure I). Statistics for paired comparisons are provided for neighboured conditions in this ordering (i.e., what is known as repeated contrasts). The contrasts revealed a decrease in the number of faithful outputs from the unmarked input $\mathrm{M}-$ to input $\mathrm{M}+\mathrm{DAT}, 93 \%$ versus $65 \%\left(F\left(\mathrm{I}, \mathrm{I}_{5}\right)=\mathrm{I}_{\mathrm{I}} \cdot \mathbf{5}^{2}\right.$, $\left.p<\cdot \mathrm{OI}, \eta^{2}=\cdot 43\right)$, and a further decrease to input $\mathrm{M}+\mathrm{FOC}, 65 \%$ versus $49 \%\left(F\left(\mathrm{I}_{1} \mathrm{I}_{5}\right)=5 \cdot 20, p<\cdot 05, \eta^{2}=\cdot 26\right)$. Inputs $\mathrm{M}+\mathrm{FOC}$ and $\mathrm{M}++\mathrm{did}$ not differ in faithfulness, $49 \%$ versus $42 \%\left(F\left(\mathrm{I}, \mathrm{I}_{5}\right)=\mathrm{I} \cdot 22\right.$, n.s., $\left.\eta^{2}=\cdot 08\right)$.

To sum up the faithfulness analysis, the order of the input forms $-\mathrm{M}-$ $>\mathrm{M}+\mathrm{DAT}>\mathrm{M}+\mathrm{FOC}=\mathrm{M}++-$ confirms that the unmarked form is most faithful, that markedness is stronger with respect to focus than with respect to word order, and that the additional marking of word order in the doubly marked form has no further effect. 

columns); grey cells indicate faithful pairs ${ }^{\dagger}$

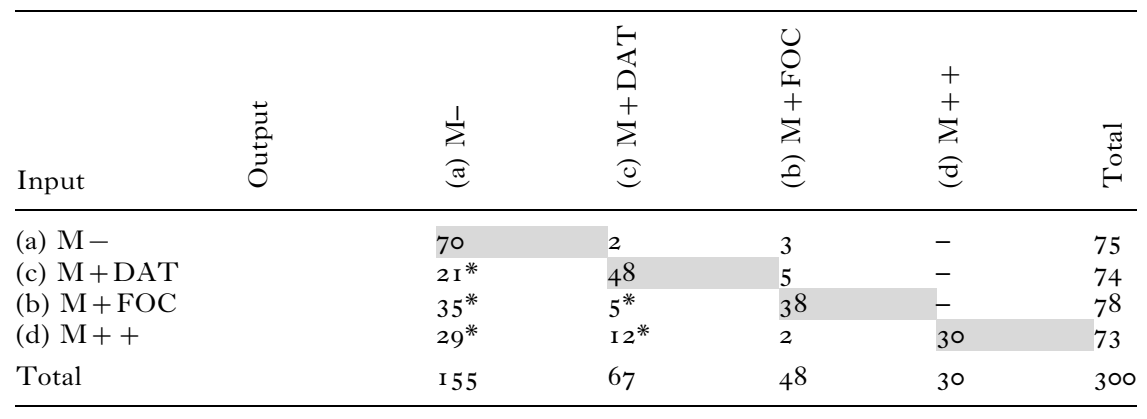

NOTE: ${ }^{\dagger}$ Unfaithful pairs with a less marked output than input are flagged with an asterisk '*'.

What do the I I 4 unfaithful input-output pairs look like (see Table I)? Only the four forms that occurred in the input occurred as unfaithful output forms; for instance, the children produced no unfaithful output by replacing the definite determiner in the input with an indefinite determiner. As the output of an unfaithful pair was expected to be less marked than its input, all unfaithful pairs with an unmarked output agree with the expectation. Indeed, $75 \%$ of the unfaithful input-output pairs $(\mathrm{N}=85)$ consisted of an unmarked output $(\mathrm{M}-$ ) to a marked input (cf. the first column of Table I : I 55-70=85). Unfaithful pairs with input $\mathrm{M}+\mathrm{FOC}$ or $\mathrm{M}++$ and output $\mathrm{M}+\mathrm{DAT}$ also meet the expectation $(\mathrm{N}=\mathrm{I} 7$; second column of Table $\mathrm{I}, 67-2-48=\mathrm{I} 7$ ). The output of the remaining $\mathrm{s} 2$ pairs ( 2 in the second column, $3+5+2$ in third column) was not less marked than the input according to the faithfulness analysis, for example, input $\mathrm{M}++$ leading to output M+FOC. Note that we opted here for the more conservative test, i.e., if the statistics confirm the hypothesis although we judged the latter two instances as counter the hypothesis, they confirm the hypothesis, too, if the two instances would have been judged as in line with the hypothesis.

We nevertheless note that a doubly marked output was never observed in an unfaithful pair. The one-sample $t$-test verified that the number of unfaithful input-output pairs that changed according to the expected direction ( $\mathrm{N}=\mathrm{I} 02 ; 89 \%)$ significantly exceeded 50\% $\left(t\left(\mathrm{I}_{3}\right)=5 \cdot 66, p<\cdot 0 \circ \mathrm{I}\right)$. Two participants are missing from this analysis because they produced no unfaithful outputs.

All in all, children's reproductions of the sentences were clearly affected by focus. This can be seen in the results most clearly in children's faithful reproductions, which were more frequent in those input conditions in 
which the focused object was the final argument of the sentence $(\mathrm{M}-$ and $\mathrm{M}+\mathrm{DAT}$ ) than in the input conditions in which the non-focused object occurred as the final argument $(\mathrm{M}+\mathrm{FOC}$ and $\mathrm{M}++)$. This suggests that the children tended to avoid uttering sentences in which focused constituents are placed before background constituents in favour of sentences with focused constituents placed after background constituents. Thus, the elicited imitations of five-year-old German children provide evidence of being sensitive to the FOC constraint. The children are also sensitive to the DAT constraint, as inputs marked for word order were less often imitated faithfully than unmarked inputs. The fact that the children reproduced sentences with a marked DO-IO word order more often faithfully than sentences with a prefinal focus further suggests that the FOC constraint is ranked higher in the child grammar than the DAT constraint, in line with Müller's proposal. Overall, we may conclude from these data that German five-year-olds are sensitive to the relation between focus and object order in ditransitive sentences.

In our next experiment we used the same technique to look at another constraint relevant for ordering the objects in double object constructions: definiteness. This time, the two objects of the input sentences contrasted in definiteness, with one object being realized as a definite DP and the other one as an indefinite DP. The order of the objects was again either dat $<$ acc (word order $\mathrm{IO}<\mathrm{DO}$ ) or acc $<$ dat (word order $\mathrm{DO}<\mathrm{IO}$ ).

\section{EXPERIMENT 2: WORD ORDER AND DEFINITENESS}

In Experiment 2, we crossed word order and definiteness to test children's adherence to the constraints DAT and DEF of Müller's subhierarchy. As before, word order in the middle field either obeyed DAT $\left(\mathrm{IO}_{\text {dat }}<\mathrm{DO}_{\text {acc }}\right)$, or disobeyed DAT $\left(\mathrm{DO}_{\mathrm{acc}}<\mathrm{IO}_{\text {dat }}\right)$. In addition, the definiteness of the two arguments either obeyed (definite <indefinite argument) or disobeyed (indefinite < definite argument) DEF. In Müller's ( I 999) proposal, DEF is ranked higher than DAT. If the grammar of five-year-old German children already ranks the constraints as proposed by Müller, we expect them to reproduce input sentences less often faithfully when they are marked for definiteness than if they are marked for word order.

\section{METHODS}

\section{Participants}

Sixteen monolingual typically developing German speaking children, aged $4 ; 5$ to $5 ; 5$ (mean: $5 ; 2$ ), eight girls and eight boys, participated in Experiment 2. The procedures for recruitment and selection of the children 
were the same as in Experiment I. None of the children tested in Experiment 2 had participated in Experiment $\mathbf{I}$.

\section{Materials}

The sentences from Experiment I served as the basis for creating the sentences used in Experiment 2 (cf. 'Appendix'). Four input forms resulted from the variation of word order and definiteness. The variation of word order is already known from Experiment I. Definiteness is unmarked if the definite DP precedes the indefinite DP, but it is marked in the opposite order. The input forms are exemplified in (6).

(6) a. M-: unmarked input

Der Mann hat $\left[\text { dem }_{\text {dat }} \text { Fungen }\right]_{\text {defIO }} \quad\left[\text { einen }_{\text {acc }} \text { Ball }\right]_{\text {indefDo }}$ gegeben.

'The man has $\left[\text { the }_{\text {dat }} \text { boy }\right]_{\text {defIO }} \quad\left[\mathrm{a}_{\mathrm{acc}} \text { ball }\right]_{\text {indefDo }}$ given.'

b. $\mathrm{M}+\mathrm{DEF}$ : input marked with respect to definiteness

Der Mann hat $\left[\text { einem }_{\mathrm{dat}} \text { Fungen }\right]_{\text {indefIO }} \quad\left[\text { den }_{\mathrm{acc}} \text { Ball }\right]_{\mathrm{defDO}}$ gegeben.

'The man has $\left[\mathrm{a}_{\mathrm{dat}} \text { boy }\right]_{\text {indefIo }} \quad\left[\text { the }_{\mathrm{acc}} \text { ball }\right]_{\mathrm{defDO}}$ given.'

c. M+DAT: input marked with respect to word order

Der Mann hat $\left[\text { den }_{\mathrm{acc}} \text { Ball }\right]_{\mathrm{defDO}} \quad\left[\text { einem }_{\text {dat }} \text { Fungen }\right]_{\text {indefIO }}$ gegeben.

'The man has $\left[\text { the }_{\text {acc }} \text { ball }\right]_{\text {defDo }}\left[\mathrm{a}_{\text {dat }} \text { boy }\right]_{\text {indefIo }}$ given.'

d. $\mathrm{M}++$ : doubly marked input

Der Mann hat $\left[\text { einen }_{\mathrm{acc}} \text { Ball }\right]_{\mathrm{indefDO}} \quad\left[\text { dem }_{\mathrm{dat}} \text { Fungen }\right]_{\mathrm{defIO}}$ gegeben.

'The man has $\left[\mathrm{a}_{\mathrm{acc}} \text { ball }\right]_{\text {indefDo }} \quad\left[\text { the }_{\mathrm{dat}} \mathrm{boy}\right]_{\mathrm{defIO}}$ given.'

Input (6a), $\mathrm{M}-$, is considered unmarked as it combines the unmarked order dat $<$ acc (word order IO $<$ DO) with an unmarked order def $<$ indef; the order indef $<$ def renders input $(6 \mathrm{~b})$ marked with respect to definiteness: $\mathrm{M}+\mathrm{DEF}$; the order acc $<$ dat (word order DO $<\mathrm{IO}$ ) renders input $(6 \mathrm{c})$ marked with respect to word order: M+DAT; input $(6 \mathrm{~d})$ is marked with respect to both definiteness and word order and is thus doubly marked: $\mathrm{M}++$.

The eighty stimulus sentences were tape-recorded at the phonetics laboratory of the University of Potsdam. They were read aloud by the same male speaker as in Experiment I, yet in a 'robot voice', that is, at a slow pace without accentuation. With the help of Praat $($ ) (Boersma \& Weenink, 2006), remaining tonal accents, i.e., Fo excursions, were eliminated and voice frequency was set to $\mathrm{r} \circ 0 \mathrm{~Hz}$ throughout. This manipulation resulted in a totally flat intonation contour, stripping the input signal of the Fo correlates of any lexical and phrasal pitch accents. The stimuli thus contained no cue as to which of the arguments was the focus exponent. Moreover, the flat intonation contour sounded somewhat unnatural; this unnaturalness, however, was partly justified by the experimental setting by the fact that the stimuli were 'uttered' by the robot character Wall-E. 
The resulting eighty stimulus sentences were distributed across four lists as in Experiment $\mathbf{I}$.

\section{Procedure}

The children were tested in the same way as in Experiment I, except that the mole Willi, before the auditory presentation of a stimulus sentence, asked a wide scope question instead of a wh-question: Was ist denn da passiert? 'What happened there?'

\section{Hypotheses}

The issues addressed are analogous to Experiment I, including our basic assumption that faithfulness decreases as markedness of inputs increases and, accordingly, that the proportion of faithful responses is highest in the case of unmarked inputs. Second, we were interested in whether markedness with respect to word order $(\mathrm{M}+\mathrm{DAT})$ leads to more or fewer unfaithful outputs than markedness with respect to definiteness $(M+D E F)$. Müller's ( I999) ranking would predict less faithful pairs in $\mathrm{M}+\mathrm{DEF}$ compared to $\mathrm{M}+\mathrm{DAT}$ as regards an adult grammar. Third, we tested again whether the doubly marked input $\mathrm{M}++$ is least faithful. Finally, we again checked whether unfaithful pairs result from marked inputs being substituted by less marked outputs.

\section{RESULTS AND DISCUSSION}

Faithfulness was analyzed as in Experiment I. The statistical analysis was based on 308 valid input-output pairs (96\%) of which I4I (46\%) were faithful. Of the twelve utterances missing in the analysis, one instance has simply not been produced. Four utterances were rejected because the 'recipient' was realized as a PP instead of an NP, again all of them with the verb wegnehmen 'to take away'. An object NP was extraposed into the 'Nachfeld' in two utterances. In four utterances, a deictic object NP was produced instead of a full NP (e.g., Die Robbe hat den Wal ein ... diesen hier gebracht, verbatim: 'The seal has the whale a ... this-one here brought'). In the final case, the child produced a completely different structure: Der Affe und der Löwe haben ihre Kämme getauscht 'The monkey and the lion have exchanged their combs' in response to the unmarked input Der Affe hat dem Löwen einen Kamm gegeben 'The monkey has given the lion a comb'. The eleven discarded utterances were distributed among the conditions as follows: $\mathrm{M}-:$ 2, $\mathrm{M}+\mathrm{DEF}:$ 2, $\mathrm{M}+\mathrm{DAT}: 4, \mathrm{M}++:$ 3. The missing utterance had an input of the form $\mathrm{M}+\mathrm{DEF}$.

The analysis confirmed that faithfulness differs significantly for the four input forms $\left(F(3,45)=20 \cdot 39, p<\cdot 00 \mathrm{I}, \eta^{2}=\cdot 58\right)$. Repeated contrasts were 


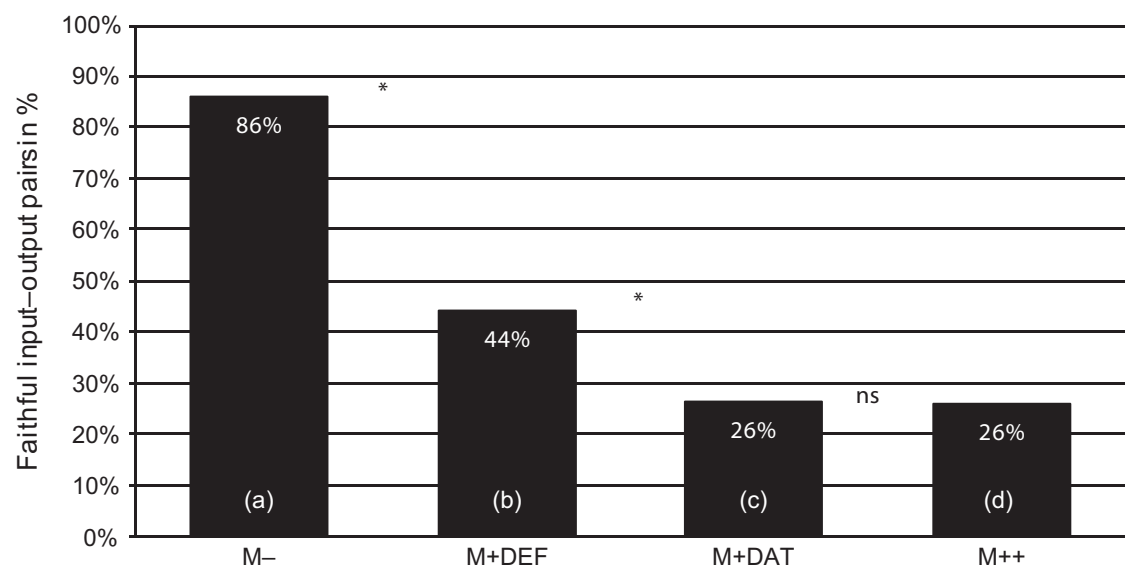

Fig. 2. Relative frequencies (in \%) of faithful input-output pairs in Experiment 2 as a function of input form (markedness for word order or/and definiteness). An asterisk between neighboured bars indicates a significant difference (ns=non-significant).

computed for the neighboured conditions in the order $\mathrm{M}-\geqslant \mathrm{M}+\mathrm{DEF}$ $\geqslant \mathrm{M}+\mathrm{DAT} \geqslant \mathrm{M}++$ (see Figure 2). Faithfulness decreased from the unmarked input $\mathrm{M}-$ to input $\mathrm{M}+\mathrm{DEF}, 86 \%$ versus $44 \%\left(F\left(\mathrm{I}, \mathrm{I}_{5}\right)=\mathrm{I}_{4} \cdot 6_{3}\right.$, $\left.p<\cdot \mathrm{OI}, \eta^{2}=\cdot 49\right)$, and it decreased further to input $\mathrm{M}+\mathrm{DAT}, 44 \%$ versus $26 \%\left(F\left(\mathrm{I}_{1} \mathrm{I}_{5}\right)=6 \cdot 02, p<\cdot 05, \eta^{2}=\cdot 29\right)$. Inputs $\mathrm{M}+\mathrm{DAT}$ and $\mathrm{M}++$ were equally faithful, both $26 \%(F<\mathrm{I})$.

To sum up the faithfulness analysis, the order of the input forms $-\mathrm{M}-$ $>\mathrm{M}+\mathrm{DEF}>\mathrm{M}+\mathrm{DAT}=\mathrm{M}++-$ confirms that the children reproduced the unmarked form more often faithfully than all other input forms. Furthermore, children reproduced sentences with the unmarked IO-DO order $(\mathrm{M}-$ and $\mathrm{M}+\mathrm{DEF})$ more often faithfully than those with the reverse object order $(\mathrm{M}+\mathrm{DAT}$ and $\mathrm{M}++)$ without any difference in faithfulness between the two latter input forms. Furthermore, input sentences that are marked only with respect to definiteness $(M+D E F)$ were more often reproduced faithfully than input sentences that are marked with respect to word order, both $\mathrm{M}+\mathrm{DAT}$ and $\mathrm{M}++$. This finding suggests that the influence of markedness is more pronounced with respect to word order than with respect to definiteness; furthermore, it does not support the assumption that the additional marking of definiteness in the doubly marked form adds to the markedness of the singly marked form M+DAT. We will take up the issue of the effect of animacy on the M+DAT condition in the 'General Discussion'.

Table 2 summarizes all input-output pairs. Out of the 167 unfaithful pairs, I I I $(66 \%)$ pairs involved an unmarked output, and thus were in 
TABLE 2. Absolute frequencies of input-output pairs (inputs in rows, outputs in columns); grey cells indicate faithful pairs ${ }^{\dagger}$

\begin{tabular}{|c|c|c|c|c|c|c|c|c|c|c|}
\hline Input & 莕 & $\underset{\Xi}{\sum_{0}^{1}}$ & 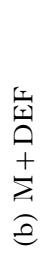 & 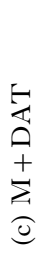 & $\begin{array}{l}+ \\
+ \\
\stackrel{+}{+} \\
\text { 。् }\end{array}$ & 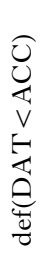 & 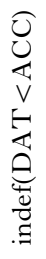 & 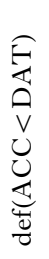 & 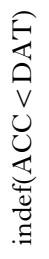 & 吾 \\
\hline (a) $\mathrm{M}-$ & & 67 & 7 & I & I & I & I & - & - & 78 \\
\hline (b) $\mathrm{M}+\mathrm{DEF}$ & & $32 *$ & 34 & - & - & $8^{*}$ & $2^{*}$ & I & - & 77 \\
\hline (c) $\mathrm{M}+\mathrm{DAT}$ & & $38^{*}$ & - & 20 & II & - & $5^{*}$ & I & I & 76 \\
\hline (d) $\mathrm{M}++$ & & $4 I^{*}$ & $8^{*}$ & I & 20 & $2^{*}$ & $2^{*}$ & $3^{*}$ & - & 77 \\
\hline Total & & I 78 & 49 & 22 & 32 & II & Io & 5 & I & 308 \\
\hline
\end{tabular}

NOTE: ${ }^{\dagger}$ Unfaithful pairs with a less marked output than input are flagged with an asterisk '*'.

accordance with our expectation that in unfaithful input-output pairs the output should be less marked than the corresponding input. For the input $\mathrm{M}+\mathrm{DEF}$, unmarked unfaithful outputs $(\mathrm{N}=32)$ were produced almost as often as faithful outputs $(\mathrm{N}=34)$. In contrast, in the conditions $\mathrm{M}+\mathrm{DAT}$ and $\mathrm{M}++$, unmarked unfaithful outputs $(\mathrm{N}=38$ and $\mathrm{N}=4 \mathrm{I}$, respectively) occurred more often than faithful outputs $(\mathrm{N}=20$ in each condition). Among the outputs that correspond to one of the input forms, eight pairs with a doubly marked input $\mathrm{M}++$ resulted in a simply marked $\mathrm{M}+\mathrm{DEF}$ output, also in line with our expectation that changes in unfaithful pairs should result in less marked outputs. In addition to outputs corresponding to one of the input forms, the children also produced outputs with both object DPs being definite or indefinite, shown in the right half of Table 2. As these outputs do not contain a definiteness contrast between the objects, they can be treated as unmarked with respect to definiteness. Hence, together with an unmarked word order, such outputs are less marked than any of the input sentences except for the unmarked input form $M-(N=$ I9). Together with a marked word order, such outputs are only less marked than the doubly marked input $\mathrm{M}++(\mathrm{N}=3)$. Overall, this more detailed inspection of the unfaithful pairs revealed that 30 of the $5^{6}$ unfaithful reproductions of the input that did not lead to an unmarked output $\mathrm{M}-$ involved a change of the input to a less marked form. Moreover, I $4 \mathrm{I}$ of the overall r 67 unfaithful pairs were in line with our expectation that unfaithful input-output pairs should show a strong bias towards a less marked output compared to the input, which was verified by a one-sample $t$-test $(\mathrm{N}=\mathrm{I} 4 \mathrm{I}$ : $84 \%)(t($ I 5$)=5 \cdot 79, p<\cdot$ ०० I $)$. 
In general, the results of Experiment 2 are in line with those of Experiment I, showing that markedness has an effect on the number of children's faithful reproductions in the different conditions, and on the direction of changes in unfaithful reproductions which consistently made the output less marked than the input. In contrast to Experiment I, Experiment 2 showed that the children overall reproduced canonical sentences with IO $<$ DO order more often faithfully than sentences with the reverse order independently of definiteness. Although a violation of DEF alone had a detrimental effect on the number of faithful reproductions, this effect was not as strong as a violation of DAT, which leads us to conclude that in the children's grammar DAT is ranked above DEF. Such a ranking disagrees with Müller's proposal for the adult grammar and suggests that the five-year-old German-learning children have not yet acquired the target grammar in this respect. We will come back to this point in the 'General Discussion'.

\section{GENERAL DISCUSSION}

The question set out at the beginning of our study was whether evidence for separate effects of focus and definiteness can be obtained in children's linearization of double objects in a controlled experimental setting. We chose to employ the elicited imitation paradigm because it allows us to disentangle the correlations between definiteness, pronominalization, and information structure typically observed in spontaneous speech or in less restricted elicitation tasks like picture description or question answering. We conducted two imitation tasks with German double object constructions with full DPs. In Experiment I, we looked at the effect of focus on linearization, in Experiment 2 we looked at the effect of definiteness. Since linearization preferences in German double object constructions seem to be affected by several factors which have been subject to broader theoretical considerations, we framed our expectations for the experiments in terms of the OT approach by Müller (I999). This account predicts linearization preferences in the adult grammar to be more strongly affected by definiteness than by focus.

The results from our two experiments show that five-year-old German learners adhere to some of the constraints that have been proposed by Müller ( I 999) to govern the ordering of objects in the German middle field: first, they favour the argument order $\mathrm{IO}<\mathrm{DO}$ over the order $\mathrm{DO}<\mathrm{IO}$, as required by the DAT constraint (Experiments I and 2); second, they prefer focused information to be placed after background information, as in the FOC constraint (Experiment I); and, finally, they favour definite DPs to precede indefinite DPs, as formulated in the DEF constraint (Experiment 2). As regards the ranking of the three constraints, children's linearization showed 
a stronger influence of FOC than of DAT in Experiment $\mathrm{I}$ and a stronger influence of DAT compared to DEF in Experiment 2. Taken together, this suggests the following ranking in the grammar of five-year-old German children: FOC $>$ DAT $>$ DEF. Compared to Müller's ( I999) proposal, $\mathrm{DEF}>\mathrm{FOC}>\mathrm{DAT}$, it may seem as if children pay less attention to definiteness than adults. Before jumping to the conclusion that one of the developmental tasks ahead of our five-year-old participants is to learn about the greater impact of the DEF constraint, one should consider alternative explanations for the pattern our participants' productions exhibited.

First, note that in Experiment I, focus was, somewhat redundantly, doubly marked by the congruency between the wh-question and the answering target sentence, and, in addition, by the pitch accent in the answer. This redundancy may be argued to have overplayed the influence of focus in Experiment $\mathrm{I}$ to a certain extent. On a similar note, the wide-scope question preceding the target sentences in Experiment 2 did not provide the participants with a given-new distinction of the two referents denoted by the object phrases, as was the case in Experiment I, where the context question established an explicit given-new distinction between the referents. It could be argued that it was this lack of discourse anchoring of our definiteness manipulation that may have produced the pattern of results that we are confronted with.

Further, one could speculate that the weaker effect of DEF could be due to the fact that the sentences in Experiment 2 were presented with a flat intonation by a robot voice, resulting in further unnaturalness, since a constituent with an indefinite article provides new information and thus would be stressed in normal discourse. Thus, further research is needed to safely establish the ranking of the constraints in the grammar of both German adults and children.

A further point deserving discussion concerns the potential effects of animacy on linearization in double object constructions. Müller ( I 999) accounts for animacy by including the constraint $\mathrm{AN}$, according to which animate objects should precede inanimate objects into his subhierarchy ScR-CRIT. In Müller's proposal, AN is ranked between DEF and FOC. It has been shown for adults that animacy can affect the ordering of constituents and the selection of sentence voice (active vs. passive) in order to put an animate argument before an inanimate one (Clark, I965, was among the first authors who demonstrated such an effect; see also Bader \& Häussler, 20ıо, for a corpus study on German object-before-subject sentences). The same principle seems to be at work in children from early on. English-learning children tend to place animate arguments before inanimate arguments by producing more passives if animate patients are paired with inanimate agents (e.g., Dewart, I979; Lempert, I989, I990). Catalan-learning children produce more sentences with left dislocations of 
the object when the object is animate compared to an inanimate object (Prat-Sala, Shillcock \& Sorace, 2000). Drenhaus and Féry (2008) observed that animacy affected children's correct dative case marking of the indirect object in German double object constructions. These findings suggest that animacy may have played a role in our studies, too.

Recall that animacy and grammatical function (DO vs. IO) were completely confounded in our materials: since we used prototypical ditransitive verbs denoting transfer or mental transfer, IOs were always animate recipients of the transfer event, and DOs were inanimate themes, i.e., the entity undergoing the transfer event. Under these circumstances, the predictions of Müller's (I 999) constraints AN and DAT regarding the ordering of the two objects are identical: the animate IO should precede the inanimate DO. The confound of DAT and AN raises a theoretical challenge and an empirical question. The theoretical challenge has its origin in the existing relationship between syntactic function and animacy, that is, most (German) ditransitive verbs select for animate recipients and inanimate themes and assign the respective case. The challenge is thus to demonstrate that the empirically observed preference for the order IO $<\mathrm{DO}$ is not itself reducible to animacy, i.e., that DAT can actually be considered an independent constraint (see Häussler \& Bader, 2012, for a recent attempt at disentangling these factors). The theoretical challenge, however, exceeds the scope of this paper. As regards the empirical question, we play on Müller's ( I 999) constraint ranking in an attempt to disentangle AN from DAT, as the two are ranked oppositely relative to FOC: AN $>$ FOC > DAT. Unfortunately, we cannot do more than to state a lack of evidence for an influence of animacy, because $\mathrm{AN}>\mathrm{FOC}$ has not been confirmed in the children's data. Whether this result is due to the ranking of $\mathrm{AN}$ below FOC in the child grammar, or whether animacy had no effect on ditransitive structures beyond DAT, cannot be decided based on our data. The theoretical challenge thus goes hand in hand with an empirical challenge which we devote to future research on language processing and acquisition in general and across languages.

As regards the confound of DAT and AN, we must reconsider whether the stronger markedness due to a violation of DAT (M+DAT) compared to a violation of $\mathrm{DEF}(\mathrm{M}+\mathrm{DEF})$ can be explained by the concurrent violation of DAT and AN, and hence by an accumulation of markedness. First, we note that Müller ( I999: 808) rejects cumulative violations (see also his note 22). Our repeated observation that the doubly marked form was not more marked than the one resulting from a single violation of the higher ranked constraint also does not support the assumption of cumulative effects. It is also striking that FOC in the children data withstood DAT, even though DAT allied with AN also in these stimuli. Thus, even if we assume that it is not DAT alone that outranked DEF but that it is DAT 
together with $\mathrm{AN}$, we must permit that $\mathrm{FOC}$ is ranked higher than DEF, again in disagreement with Müller's ranking DEF $>$ DAT.

We now come back to our question whether children show effects of information structure (i.e., focus in our experiment) and definiteness on their orderings - the question which was the starting point of our study. With respect to focus, our data suggest that this is the case. The clearest evidence for this is provided by the fact that the proportions of faithful reproductions were highest for the input sentences in which the focus induced by the question preceding the sentence occurred in the rightmost argument position including those input sentences in which the IO filled this position. A closer look at the unfaithful reproductions shows that a considerable amount of these outputs were sentences in which the nuclear accent occurred in the rightmost position, despite the fact that this position was not filled by the constituent that should be focused as a felicitous answer to the question. In these cases the children produced the unmarked sentence $\mathrm{M}-$, which would be the expected output in a wide-scope context. We do not think that these kinds of unfaithful reproductions indicate that children have problems in prosodically marking a focused constituent in an experimental setting in which the focus is induced by using question-answer pairs. In a study with a similar imitation task also using question-answer pairs in which the answers were presented with a flat intonation contour, Müller et al. (2006) were able show that German four-year-olds mark a focused subject or object-depending on the type of question - appropriately by the use of prosodic means. This suggests that specific aspects of the procedure in our task may have masked the question-answer relations in some cases for the children, resulting in the production of the most unmarked form-prosodically as well as with respect to word order.

However, even though we cannot give a detailed explanation of these kinds of outputs, they suggest that children have a bias to produce prosodically unmarked structures with the nuclear accent on the rightmost position and that this bias can overrule the DAT constraint as exemplified by the relatively high number of unfaithful outputs in our M+DAT condition. This also points to the fact that linearization principles should not be considered independently of prosodic principles in a given language. The fact that the interaction of information status and prosodic structure may not be fully understood so far may also contribute to the heterogeneous picture that arose with respect to the impact of information structure on word order in the previous studies reported in the 'Introduction' (de Marneffe et al., 2012; Hickmann et al., I996; Narasimhan \& Dimroth, 2008; Stephens, 2010).

With respect to definiteness, the crucial comparison is between (i) the outcomes of the sentences with an unmarked IO $<$ DO order that only 
differed with respect to the definiteness with either a definite IO and an indefinite DO (which is the unmarked case), and (ii) sentences with an indefinite IO and a definite DO (being the marked case with respect to definiteness).

Recall that the unmarked sentences were reproduced faithfully in about $86 \%$ of the cases, while only $44 \%$ of the sentences marked with respect to definiteness were reproduced faithfully. Of the unfaithful reproductions, $75 \%$ showed a switch in definiteness by marking the IO as definite and the DO as indefinite, resulting in an unmarked structure with respect to definiteness. In the remaining cases of unfaithful reproductions, the definiteness contrast was eliminated by marking both arguments as either definite or indefinite. Remember that in this experiment the input sentences were preceded by a wide scope question 'What has happened there?' As pointed out before, there were no discourse related factors which affected the status of the two objects with respect to the given-new distinction which, among other factors, typically is associated with the use of definite and indefinite articles. Thus, we conclude from our data that definiteness can affect the children's ordering preferences independently of (discourse) givenness.

An additional, methodological, outcome of our findings is the fact that the elicited imitation task we used seems to be a suitable means to test children's sensitivity to violable constraints in grammar. In previous studies using this task successfully, mostly children's responses to violations leading to ungrammaticality have been tested (Lust et al., I996), demonstrating that - in correspondence with their grammatical knowledge-children change ungrammatical input sentences to grammatical output sentences. Our study has shown that children's ability to reproduce a given input sentence in this kind of task is also sensitive to the relatively subtle markedness differences of grammatical sentences, with a strong tendency to change more marked to less marked structures (see also Barbier, 2000). This experimental paradigm thus provides a suitable means to test children's sensitivity to gradience and optionality in a controlled experimental procedure and allows for disentangling factors that are often highly correlated in spontaneous speech, or in utterances elicited in tasks very close to spontaneous speech, like picture description tasks. It might be interesting to note that practice did not influence faithfulness during the experimental sessions, suggesting that the effects observed in the experiment were not induced by presenting the children a range of sentences with word order variation in the task itself. This was tested by computing Spearman's rank correlation for trial number (rank of practice) with rank in faithfulness, for which we determined for each of the twenty trials the relative frequency of faithful outputs across all participants of both experiments and fed the ranks into the analysis. The analysis did not yield any hint to a practice effect. 
To summarize: to the best of our knowledge, this is the first study looking at the factors that influence how children learn to linearize double objects in the German middle field. The findings reveal that children below school age are sensitive to markedness of word order and, moreover, that they adhere to relevant constraints that have been claimed to underlie object ordering preferences in the grammar of German speakers. Using an elicited imitation task our study provides experimental evidence that both the focus constraint and the definiteness constraint have an independent impact on German children's ordering of objects. Our data support the findings from Stephens (2010) for the given-new contrast in English-learning children and extend them to another category of information structure and to German as a language that shows a much higher degree in word order variation than English. Our results jointly suggest that children at preschool age prefer to produce word orders with new or focused information following given or background information in double object constructions, which is in line with adults' performance in both languages. Furthermore, we were able to demonstrate that focus has an effect on the ordering of arguments that are both full NPs in children's production, suggesting an impact of information structure independently from the choice of referring expression (pronominalization, definiteness). Though we cannot rule out the possibility that our results were affected by children's preference for producing an unmarked prosodic structure, our findings are compatible with the view that children have some abstract categories of information structure available. However, a direct test of this hypothesis would require a task in which information structure is pitted against structural features related to markedness - a condition that was not included in our experiments but that deserves consideration in further research.

Some final remarks should be made regarding the question of how children acquire the ability to linearize the arguments of ditransitive verbs. Corpus analyses of German children's production and of the speech directed at them suggests that variation in the ordering of objects of ditransitive verbs occurs in the input as well as in children's own utterances from early on (Sauermann \& Höhle, 20r3). Interestingly, the analysis of the ordering patterns of children and adults also showed that word order was affected by information structure: a marked word order with the DO preceding the IO (here in the prefield) was more likely when the DO referred to given information than when it referred to new information. The analysis of the child-directed speech also revealed that the class of ditransitive verbs that occurred repeatedly with different orderings of the arguments was rather small, but included highly frequent verbs like geben 'to give' or bringen 'to bring'. These verbs are characterized by a rather homogeneous and semantically transparent argument structure - typically an animate recipient as the IO and an inanimate theme as the DO. This transparent mapping of 
semantic and syntactic properties in combination with the rather frequent occurrence of the specific verbs may increase the salience of the variation in the order of the arguments for the children. This in turn may provide the basis for the detection of the ranking of the constraints underlying the ordering of objects in German.

\section{REFERENCES}

Bader, M. \& Häussler, J. (2010). Toward a model of grammaticality judgments. Fournal of Linguistics 46, 273-330.

Barbier, I. (2000). An experimental study on scrambling and object shift in the acquisition of Dutch. In S. M. Powers \& C. Hamann (eds.), The acquisition of scrambling and cliticiziation, 4I-70. Dordrecht: Kluwer Academic Publishers.

Bock, J. K. \& Irwin, D. E. (I980). Syntactic effects of information availability in sentence production. Fournal of Verbal Learning and Verbal Behavior 19, 467-84.

Boersma, P. \& Weenink, D. (2006). Praat: doing phonetics by computer (Version 4.4.20) [computer program]. Retrieved from <http://www.praat.org/ $>$.

Bresnan, J. (2007). Is syntactic knowledge probabilistic? Experiments with the English dative alternation. In S. Featherston \& W. Sternefeld (eds.), Roots: linguistics in search of its evidential base, 77-96. Berlin: Mouton de Gruyter.

Büring, D. (200I). What do definites do that indefinites definitely don't? In C. Féry \& W. Sternefeld (eds.), Audiator vox sapientiae - a Festschrift for Arnim von Stechow (Studia Grammatica 52), 70-100. Berlin: Akademie Verlag.

Chafe, W. (1976). Givenness, contrastiveness, definiteness, subjects, topics, and point of view. In C. Li (ed.), Subject and topic, 25-55. New York: Academic Press.

Chen, A. (20Ir). Tuning information packaging: intonational realization of topic and focus in child Dutch. Fournal of Child Language 38, $1055-83$.

Clark, H. H. (1965). Some structural properties of simple active and passive sentences. Fournal of Verbal Learning and Verbal Behavior 4, 365-70.

Clark, H. H. \& Haviland, S. E. (I977). Comprehension and the given-new contract. In R. O. Freedle (ed.), Discourse production and comprehension, I-40. Norwood, NJ: Ablex.

De Marneffe, M.-C., Grimm, S., Arnon, I., Kirby, S. \& Bresnan, J. (2012). A statistical model of the grammatical choices in child production of dative sentences. Language and Cognitive Processes 27, 25-61.

De Ruiter, L. (2010). Studies on intonation and information structure in child and adult German. Unpublished PhD thesis, Max Planck Institute for Psycholinguistics, Nijmegen.

Dewart, M. H. (I979). The role of animate and inanimate nouns in determining sentence voice. British Fournal of Psychology 30, 495-501.

Drenhaus, H. \& Féry, C. (2008). Animacy and child grammar: an OT account. Lingua Ir8, $222-44$.

Emslie, H. C. \& Stevenson, R. J. (I98I). Pre-school children's use of the articles in definite and indefinite referring expressions. Fournal of Child Language 8, 3 $13-28$.

Fanselow, G. (200I). Features, $\theta$-roles, and free constituent order. Linguistic Inquiry 32(3), 405-37.

Ferreira, V. S. \& Yoshita, H. (2003). Given-new ordering effects on the production of scrambled sentences in Japanese. Fournal of Psycholinguistic Research 32, 669-92.

Féry, C. (1 993). German intonational patterns. Tübingen: Niemeyer.

Grimm, H. (2003). SSV-Sprachscreening für das Vorschulalter. Göttingen: Hogrefe.

Gussenhoven, C. (1983). Focus, mode and the nucleus. Fournal of Linguistics 19, 377-4I 7.

Häussler, J. \& Bader, M. (20I2). Grammar- versus frequency-driven syntactic ambiguity resolution: the case of double-object constructions. In M. Lamers \& P. de Swart 
(eds.), Case, word order and prominence: interacting cues in language production and comprehension, 273-301. Dordrecht: Springer.

Heim, I. (1982). The semantics of definite and indefinite noun phrases. New York: Garland.

Hickmann, M., Hendriks, H., Roland, F. \& Liang, J. (I996). The marking of new information in children's narratives: a comparison of English, French, German, and Mandarin Chinese. Fournal of Child Language 23, 59 I-6 го.

Höhle, T. N. (1982). Explikation für 'normale Betonung' und 'normale Wortstellung'. In W. Abraham (ed.), Satzglieder im Deutschen: Vorschläge zur syntaktischen, semantischen und pragmatischen Fundierung, 75-1 53. Tübingen: Narr.

Hornby, P. A. \& Hass, W. A. (I970). Use of contrastive stress by preschool children. Fournal of Speech and Hearing Research 13, 395-99.

Kail, M. \& Hickmann, M. (I992). French children's ability to introduce referents in narratives as a function of mutual knowledge. First Language 12, 73-94.

Kail, M. \& Sanchez y Lopez, I. (I997). Referent introduction in Spanish narratives as a function of contextual constraints: a crosslinguistic perspective. First Language 17, 103-30.

Kauschke, C. \& Siegmüller, J. (2002). Patholinguistische Diagnostik bei Sprachentwicklungsstörungen. München: Urban und Fischer.

Keller, F. (2000). Gradience in grammar: experimental and computational aspects of degrees of grammaticality. Unpublished $\mathrm{PhD}$ thesis, University of Edinburgh.

Legendre, G., Grimshaw, J. \& Vikner, S. (200I). Optimality-theoretic syntax. Cambridge, MA: MIT Press.

Lempert, H. (I989). Animacy constraints on preschool children's acquisition of syntax. Child Development 6o, 237-45.

Lempert, H. (1990). Acquisition of passives: the role of animacy, salience, and lexical accessibility. Fournal of Child Language 1 7, 677-96.

Lenerz, J. (1977). Zur Abfolge nominaler Satzglieder im Deutschen. Tübingen: Narr.

Lust, B., Flynn, S. \& Foley, C. (I996). What children know about what they say: elicited imitation as a research method for assessing children's syntax. In D. MacDaniel, C. McKee \& H. Smith Cairns (eds.), Methods for assessing children's syntax, 55-76. Cambridge, MA: MIT Press.

Lyons, C. (I 999). Definiteness. Cambridge: Cambridge University Press.

MacWhinney, B. \& Bates, E. (1978). Sentential devices for conveying givenness and newness: a cross-cultural developmental study. Fournal of Verbal Learning and Verbal Behavior 17, 539-58.

Maratsos, M. P. (I974). Preschool children's use of definite and indefinite articles. Child Development 45, 446-55.

Müller, A., Höhle, B., Schmitz, M. \& Weissenborn, J. (2006). Focus-to-stress alignment in 4 to 5-year old German-learning children. In A. Belletti, E. Bennati, C. Chesi, E. Di Domenico \& I. Ferrari (eds.), Language acquisition and development. Proceedings of GALA 2005, 393-407. Cambridge: Cambridge Scholars Press.

Müller, G. (1999). Optimality, markedness, and word order in German. Linguistics 37, $777-8$ I 8 .

Musolino, J. \& Lidz, J. (2006). Why children aren't universally successful with quantification. Linguistics 44, 8 17-54.

Narasimhan, B. \& Dimroth, C. (2008). Word order and information status in child language. Cognition 107, 3 I 7-29.

Power, R. J. D. \& Dal Martello, M. F. (1986). The use of definite and indefinite articles by Italian preschool children. Fournal of Child Language 13, I45-54.

Prat-Sala, M., Shillcock, R. \& Sorace, A. (2000). Animacy effects on the production of object-dislocated descriptions by Catalan-speaking children. Fournal of Child Language 27, 97-II 7 .

Prince, A. \& Smolensky, P. (I 993). Optimality Theory: constraint interaction in generative grammar. Unpublished manuscript, Rutgers University, New Brunswick and University of Colorado, Boulder. 
Reis, M. (1987). Die Stellung der Verbargumente im Deutschen. Stilübungen zum Grammatik-Pragmatik-Verhältnis. In I. Rosengren (ed.), Sprache und Pragmatik. Lunder Symposium 1986, I39-I77. Stockholm: Almqvist \& Wiksell.

Ross, J. R. (1967). Constraints on variables in syntax. Unpublished PhD dissertation, MIT.

Sauermann, A. \& Höhle, B. (2013). Corpus investigation of information structural ordering preferences in German-speaking children and adults. In S. Stavroula, M. Lalioti \& $\mathrm{X}$. Konstantinopoulou (eds.) Advances in Language Acquisition. Cambridge: Cambridge Scholars Publishing.

Sauermann, A., Höhle, B., Chen, A. \& Järvikivi, J. (20I I). Intonational marking of focus in different word orders in German children. In M. Byram Washburn, K. McKinneyBock, E. Varis, A. Sawyer \& B. Tomaszewicz (eds.), Proceedings of the 28th West Coast Conference on Formal Linguistics, 313-22. Somerville, MA: Cascadilla Proceedings Project.

Schaeffer, J. \& Matthewson, L. (2005). Grammar and pragmatics in the acquisition of article systems. Natural Language \& Linguistic Theory 23, 53-гог.

Selkirk, E. (1 995). Sentence prosody: intonation, stress, and phrasing. In John A. Goldsmith (ed.), The handbook of phonological theory, 550-69. London: Blackwell.

Stephens, N. (2010). Given-before-new: the effects of discourse on argument structure in early child language. Unpublished $\mathrm{PhD}$ thesis, University of Stanford.

Trueswell, J. C., Sekerina, I., Hill, N. M. \& Logrip, M. L. (I999). The kindergarten-path effect: studying on-line sentence processing in young children. Cognition 72, 89-1 34 .

Uszkoreit, H. (I 986). Constraints on order. Linguistics 24, 883-906.

Wieman, L. A. (1976). Stress patterns in early child language. Fournal of Child Language 3 , $283-86$.

Wonnacott, E. \& Watson, D. G. (2008). Acoustic emphasis in four year olds. Cognition ro7, IO93-IOI. 
APPENDIX: LEXICAL SENTENCE VARIANTS USED IN EXPERIMENTS I AND 2

\begin{tabular}{|c|c|c|c|}
\hline Verb (V) & Subject $(\mathrm{S})$ & Indirect object (IO) & Direct object (DO) \\
\hline \multirow[t]{4}{*}{ geben 'to give' } & Mann 'man' & Funge 'boy' & Ball 'ball' \\
\hline & Affe 'monkey' & Löwe 'lion' & Kamm 'comb’ \\
\hline & Tante 'aunt' & Baby 'baby' & Teddy 'teddy' \\
\hline & Spatz 'sparrow' & Storch 'stork' & Zweig 'twig' \\
\hline \multirow{4}{*}{ bringen 'to bring' } & Hexe 'witch' & Vampir 'vampire' & Umhang 'cape' \\
\hline & Robbe 'seal' & Wal 'whale' & Reifen 'tyre' \\
\hline & Hund 'dog' & Bauer 'farmer' & Stiefel 'boot' \\
\hline & Gespenst 'ghost' & Drachen 'dragon' & Schlüssel 'key’ \\
\hline \multirow[t]{4}{*}{ schenken 'to donate' } & Eule 'owl' & Rabe 'raven' & Stein 'stone' \\
\hline & Spinne 'spider' & Käfer 'beetle' & Hut 'hat' \\
\hline & Papa 'daddy' & Kind 'child' & Roller 'kick scooter' \\
\hline & Riese 'giant' & Zwerg 'dwarf' & Kran 'crane' \\
\hline \multirow[t]{4}{*}{ zeigen 'to show' } & Maus 'mouse' & Frosch 'frog' & See 'lake' \\
\hline & Fee 'fay' & Ritter 'knight' & Schatz 'treasure' \\
\hline & Pirat 'pirate' & König 'king' & Ring 'ring' \\
\hline & Biene 'bee' & $B \ddot{a r}$ 'bear' & Baum 'tree' \\
\hline \multirow[t]{4}{*}{ wegnehmen 'to take away' } & Räuber 'robber' & Clown 'clown' & Schuh 'shoe' \\
\hline & Igel 'hedgehog' & Pferd 'horse' & Apfel 'apple' \\
\hline & Schaf 'sheep' & Mädchen 'girl' & Strumpf 'stocking' \\
\hline & Teufel 'devil' & Engel 'angel' & Keks 'cookie' \\
\hline
\end{tabular}

